\title{
Unusual presentation of a case of ovarian endometrioma
}

\author{
Rini Rajiv Sutaria*, Meena Naresh Satia, V. R. Badhwar
}

Department of Obstetrics and Gynecology, Dr. D. Y. Patil Medical College and Hospital, Pune, Maharashtra, India

Received: 01 June 2018

Accepted: 28 June 2018

\section{*Correspondence:}

Dr. Rini Rajiv Sutaria,

E-mail: rini.sutaria@gmail.com

Copyright: (c) the author(s), publisher and licensee Medip Academy. This is an open-access article distributed under the terms of the Creative Commons Attribution Non-Commercial License, which permits unrestricted non-commercial use, distribution, and reproduction in any medium, provided the original work is properly cited.

\begin{abstract}
Ca-125 is a cell surface glycoprotein present in epithelial ovarian tumors. It is called as a biomarker because it provides information about the biological state of a disease. It is also considered a "tumor associated protein" because elevated CA 125 levels do not always indicate ovarian cancer. Pelvic inflammatory disease irritable bowel disease, tuberculosis pancreatitis and endometriosis can also increase the Ca125 levels in these benign conditions the Ca 125 levels are rarely markedly. Here authors report a case of ovarian endometrioma with markedly elevated levels of Ca 125 who was diagnosed as a case of ovarian malignancy due to presence of ascites and a large ovarian mass of 20x20 $\mathrm{cm}$ size arising from the pelvis.
\end{abstract}

Keywords: CA 125, Endometriosis, Pelvic inflammatory disease

\section{INTRODUCTION}

Normal healthy tissues like ovarian, breast and pancreas, and the visceral covering of the abdomen and chest all produce and release low levels of $\mathrm{Ca} 125$. Since the $\mathrm{Ca}$ 125 test reflects the amount of protein often called antigen, released and circulated into the blood, conditions that "disturb the silence" change the test result. Ovarian cancer in addition to increasing the number of cells that make $\mathrm{Ca} 125$ also causes disturbance and inflammation of the abdominal lining which contains "normal" cells that make and release $\mathrm{Ca} 125$. Therefore $\mathrm{Ca} 125$ is elevated in ovarian cancer and in some other cancers in the abdomen. Inflammatory conditions of the abdomen like endometriosis PID inflammatory bowel disease, tuberculosis and pancreatitis can also increase the CA12levels. ${ }^{1}$ In some situations, Ca 125 is even used to monitor the effects of treatment for benign conditions such as endometriosis which must be considered in the interpretation of an elevated $\mathrm{Ca} 125$ value. $^{2}$ In endometriosis the levels of ca 125 is elevated but rarely markedly elevated to $6999.9 \mathrm{IU} / \mathrm{ml}$. In studied patient in addition to Ca 125 levels markedly elevated even LDH level was double the normal levels so the biochemical markers pointed towards ovarian malignancy, but histopathology reported it to be ovarian endometrioma containing normal endometrial glands and stroma.

\section{CASE REPORT}

A 38 years old patient Para 4 came with complains of pain in abdomen since 6 months with something coming out of vagina since 5-6 months. She also noticed distension of abdomen since last 2 months. Patient had complained of gaseous distension with bloating sensation and constipation. She was known case of diabetes mellitus since 5 years. Patient did complain of menorrhagia since last 3-4 cycles but had no dysmenorrhea. On general examination her vital parameters were stable On per abdominal examination she had a 22 weeks size mobile mass with ascites Per vaginal examination showed uterus retroverted normal size with 22 wks freely mobile mass felt separately from uterus in the right fornix Pre-operative work-up was normal Ca 125 levels was markedly elevated to 6999.9 
IU/ml, Serum AFP -2.4 ng/ml, CEA -2.4 ng/ml, Serum LDH - 939.7 IU/l, $\beta$ Hcg was $<0.050 \mathrm{miu} / \mathrm{ml}$. sonography report showed $20.3 \times 16.2 \times 16.3 \mathrm{~cm}$ well defined hetrogenously hyperechoic lesion arising from right adnexa from which both ovaries are not seen separately, with septation and mild peripheral vascularity within. So, a provisional diagnosis of ovarian neoplasm with 2 nd degree uterine prolapse was made. Then CT scan was advised which showed images as follows in Figure 1 and Figure 2.

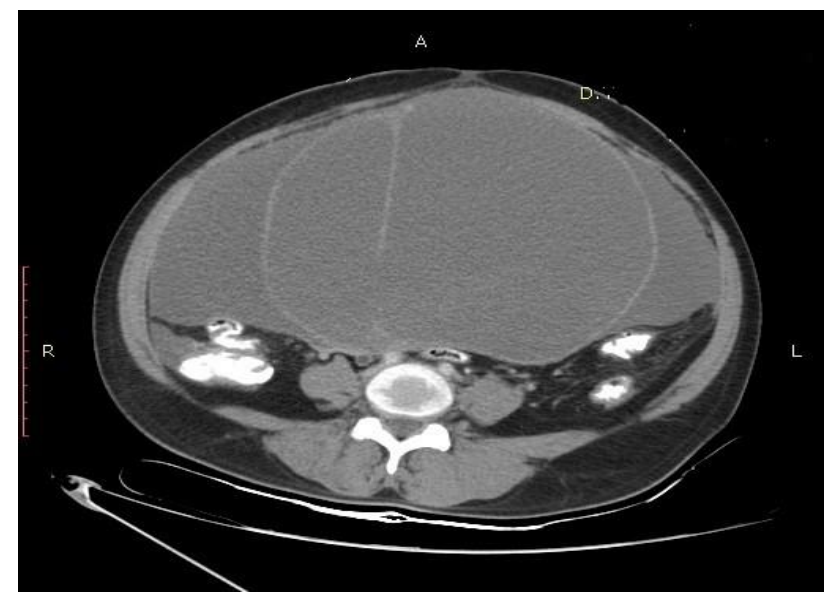

Figure 1: CT Scan of cystic lesion with septae coming from left adnexa with ascites.

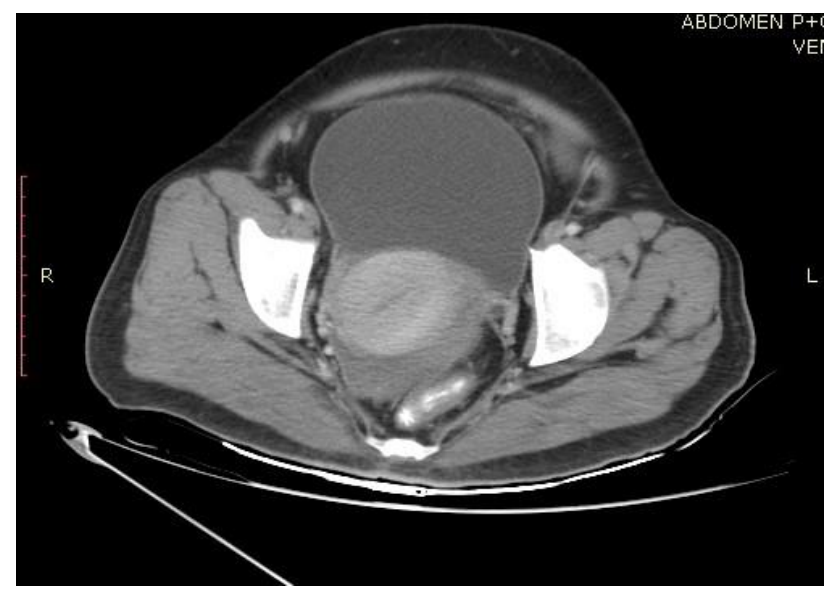

Figure 2: CT Scan of bladder, with normal size of uterus and sigmoid colon.

CT Scan report showed large well defined multi-septate solid cystic lesion measuring $18.2 \times 16.7 \times 16.4 \mathrm{~cm}$ arising from pelvis upto supraumbilical and epigastric region. $8.5 \times 3.5 \mathrm{~cm}$ solid component seen at its inferior aspect. Another similar cystic lesion measuring $7.5 \times 6.4 \times 5.4 \mathrm{~cm}$ is seen arising from pouch of douglas with moderate free fluid in abdomen and pelvis and mild diffuse omental thickening.

A clinical impression of ovarian malignancy was made and patient was posted for Total Abdominal Hysterectomy with bilateral Salpingo-oopherectomy
Abdomen was opened by vertical midline infraumbilical incision. Findings showed a $20 \mathrm{~cm}$ mass arising from left ovary. The sigmoid colon was adherent to the mass. The cyst was free from all other abdominal structures. While delivering the cyst out of incision, cyst ruptured and thick chocolate colored fluid oozed out. 2 litres of the same was collected. Dense adhesions between the sigmoid and the lower lobe of the mass were removed by sharp dissection Intra-operative findings were as shown in Figure 3 and Figure 4.

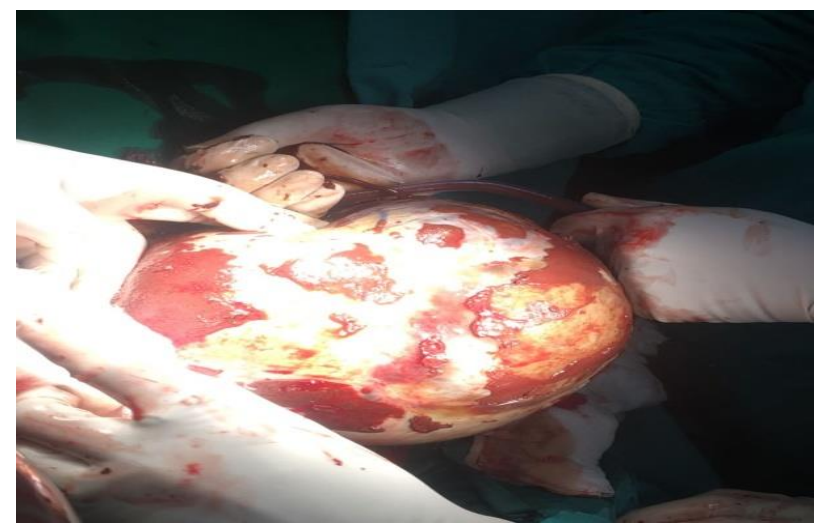

Figure 3: Intra operative image of ovarian mass.

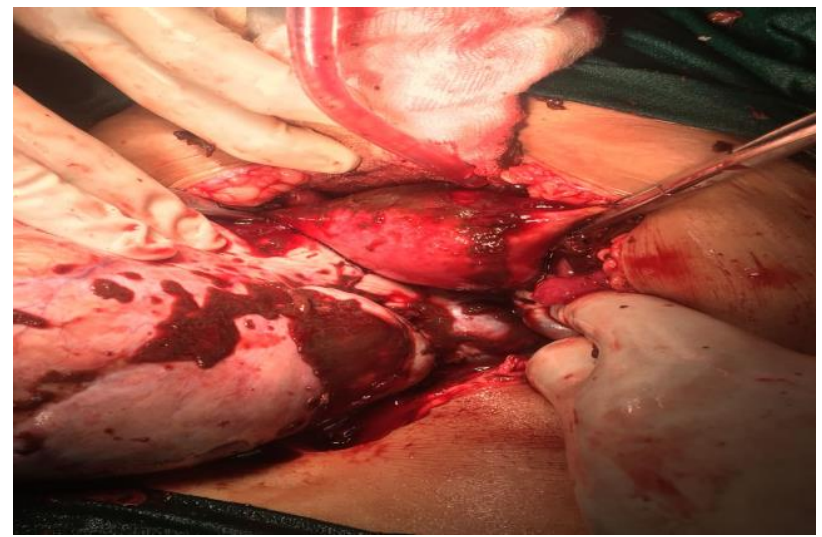

Figure 4: Intra operative image of normal sized uterus with ruptured ovarian cyst with chocolate colored fluid.

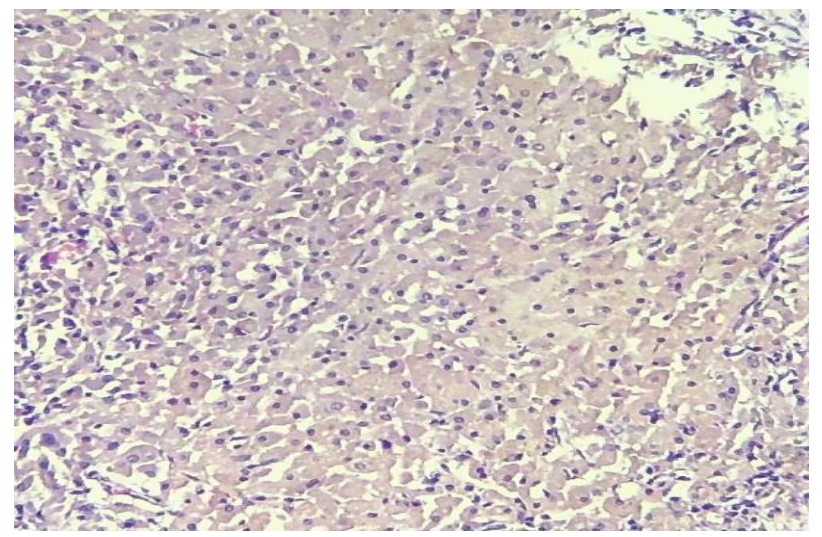

Figure 5: Endometrial glands and stroma. 
Cyst removal done and sent for histopathology. Total abdominal hysterectomy with bilateral Salpingoophrectomy was performed Peritoneal wash cytology did not show any malignancy.

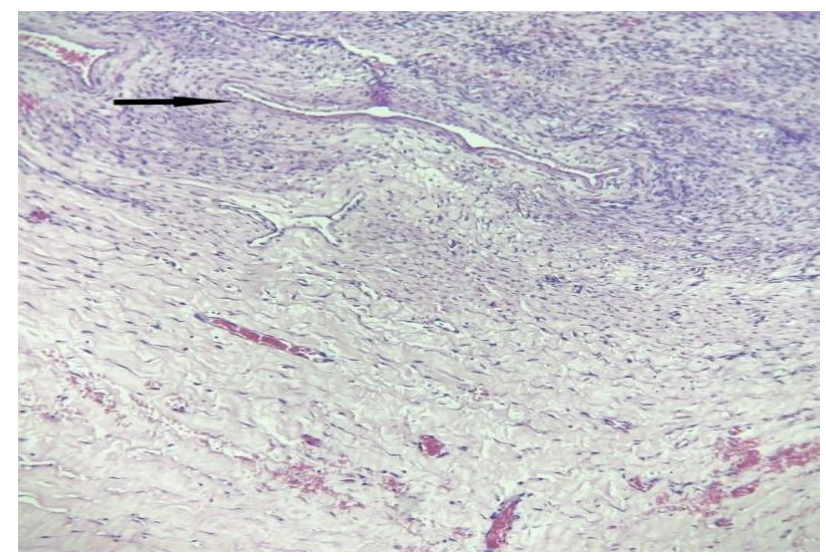

Figure 6: Hemosiderin laden macrophages.

\section{DISCUSSION}

Endometriosis though a benign condition can spread in a cancer like fashion and create extensive havoc in the pelvis resulting in dense adhesions anteriorly with the bladder and posteriorly with the bowel. Extensive inflammation of the peritoneum results in markedly elevated levels of $\mathrm{Ca} 125$. Ovarian endometriomas occur in $17-44 \%$ of women with endometriosis. ${ }^{3}$ Their size may range from $0.75-8$ inches and it rarely exceeds $10-15 \mathrm{~cm}$ in diameter. ${ }^{4,5}$ Malignancy is suspected if diameter of ovarian mass is more than $10 \mathrm{~cm}^{.6-8}$

The overflow of thick chocolate fluid in peritoneal cavity induces peritoneal inflammation leading to congestive dysmenorrhea, pelvic pain, dyspareunia, menorrhagia, low parity/infertility, adhesions to pelvic and abdominal contents and excess Ca-125 levels in circulation. Half-life of $\mathrm{Ca} 125$ is approximately 5 days. Extensive inflammation of the peritoneum can result in markedly increased levels of $\mathrm{Ca}$ 125.These levels have more of prognostic significance as compared to diagnostic. Approximately $80 \%$ of epithelial tumors will have an elevated CA-125 level at the time of diagnosis. ${ }^{9}$ Measuring Ca-125 level may predict cancer more accurately in postmenopausal women, with specificity values reported at $98.5 \%$ for women older than $50 .{ }^{10} \mathrm{Ca}$ 125 levels over time provides a more accurate assessment of ovarian cancer than one-time measurement. ${ }^{11}$

Prolapse is not a usual complain as the uterus is retroverted and fixed. Elevations of $\mathrm{Ca} 125$ above the reference interval after debulking surgery and chemotherapy indicate that residual disease is likely with $>95 \%$ accuracy. However, normal levels do not rule-out recurrence. A persistently rising $\mathrm{Ca} 125$ value suggests progressive malignant disease and poor therapeutic response. It is not only widely employed to detect recurrent ovarian cancer in women who have been previously treated but also for monitoring throughout the course of chemotherapy to assess effectiveness

\section{CONCLUSION}

The $\mathrm{Ca} 125$ test is used during the course of the diagnosis, treatment and follow-up of ovarian and other closely related lesions like endometriosis. Ca 125 has been studied for its ability to predict treatment outcome for women with ovarian cancer as well as endometriosis. This blood test is often used to screen for ovarian, primary peritoneal and fallopian tube cancers in high-risk women, or in women with abnormal findings on examination or ultrasound.

Funding: No funding sources

Conflict of interest: None declared

Ethical approval: Not required

\section{REFERENCES}

1. Graham L. ACOG releases guidelines on management of adnexal masses. Am Fam Physician. 2008;77(9):1320-3.

2. Understanding CA 125 Levels A guide for ovarian cancer patients. Available at http://www.foundationforwomenscancer.org/wpcontent/uploads/CA125levels.pdf

3. Keyhan S, Hughes C, Price T, Muasher S. An update on surgical versus expectant management of ovarian endometriomas in infertile women. BioMed research Int. 2015;2015.

4. Fedele L, Bianchi S, Bocciolone L, Di GN, Parazzini F. Pain symptoms associated with endometriosis. Obstet Gynecol. 1992;79(5 (Pt 1)):767-9.

5. Clement PB. Diseases of the peritoneum. In Blaustein's pathology of the female genital tract 1994 (pp. 647-703). Springer, New York, NY.

6. Hesla JS, Rock JA. Endometriosis. In: Rock JA, Jones HW (eds) Te Linde's operative gynecology, $9^{\text {th }}$ edn. Lipincott-Raven, Philadelphia. 2033:599-603.

7. Ishikawa H, Taga M, Haruki A, Shirasu K, Minaguchi H, Hara M. Huge ovarian endometrial cyst: a case report. Eur J Obstet Gynecol Reprod Biol. 1997;74(2):215-7.

8. Reuter KL, Davidoff A, Cooney JV, Hunter RE. An unusually large endometrioma simulating an ovarian malignancy. Am J Roentgenol. 1988;151(4):834-5.

9. Salani R, Backes FJ, Fung MF, Holschneider CH, Parker LP, Bristow RE, Goff BA. Posttreatment surveillance and diagnosis of recurrence in women with gynecologic malignancies: Society of gynecologic oncologists recommendations. Am J Obstet Gynecol. 2011;204(6):466-78.

10. Einhorn N, Sjövall K, Knapp RC, Hall P, Scully RE, Bast RC Jr, et al. Prospective evaluation of serum CA 125 levels for early detection of ovarian cancer. Obstet Gynecol. 1992;80(1):14-8. 
11. Skates SJ, Menon U, MacDonald N, Rosenthal AN, Oram DH, Knapp RC, et al. 7 Calculation of the risk of ovarian cancer from serial CA-125 values for preclinical detection in postmenopausal women. $\mathrm{J}$ Clin Oncol. 2003;21(10 Suppl):206s-210s.
Cite this article as: Sutaria RR, Satia MN, Badhwar VR. Unusual presentation of a case of ovarian endometrioma. Int J Reprod Contracept Obstet Gynecol 2018;7:3403-6. 